\title{
Applanation tension and axial length of the eyeball
}

\author{
A. TOMLINSON aNd G. I. PHILLIPS
}

Department of Ophthalmology, University of Manchester, and Manchester Royal Eye Hospital

Armaly ( 1967 a) found, from two independent studies of first-degree relatives with clinically normal eyes, that the level of ocular tension is genetically determined and that the mode of inheritance is polygenic multifactorial in nature. In a previous study (Armaly, I966), he showed that the applanation tension in one partner of a marital pair is independent of the other's, which led to the conclusion that environmental influence is small.

The effects of age and sex on ocular tension have also been evaluated (Armaly, r962), and from an extensive population survey it was concluded that a significant difference in tension exists between different age groups, both Schiötz and applanation readings becoming higher and $\mathrm{G}$ values becoming lower with advancing age. In a later paper, however, Armaly (1967b) found that the effect of age and sex was limited to the age groups over 45 years; women in these groups have significantly higher means of applanation and Schiötz readings than men.

The present survey concerns:

(a) The relationship of axial length of the eyeball to its tension;

(b) The differences in ocular tension between myopes, hypermetropes, and emmetropes;

(c) The effect of the sex of subjects within the same age group on applanation tension.

\section{Subjects}

For the part of this survey concerned with $(a)$ and $(c)$ above, the same individuals who had been studied for the determination of the relationship between the cup-to-disc ratio and the length of the eyeball (Tomlinson and Phillips, 1969) were used, i.e. 75 undergraduate students. Their ages were between 18 and 27 years; 26 were female and 49 male. The result from only one eye of each subject was used for statistical purposes: it was randomly selected by the toss of a coin ( 36 right, 39 left).

For the study of $(b)$ above, to this original sample were added the results from a group of nineteen normal persons whose ages varied between 26 and 72 years, making a grand total of 94 subjects. Of the nineteen additional subjects, twelve were female and seven male, and thirteen left eyes and six right eyes were included. The reason for adding to the original sample of 75 was that the difference in applanation tension between the refractive groups did not quite reach the 5 per cent. level of significance (although the correlation between applanation tension and axial length did); wider ranges of refractive errors therefore became available, from a range of $-7 \mathrm{D}$ to $+4 \cdot 75 \mathrm{D}$ in the sample of 75 to a range of $-9 \cdot 5 \mathrm{D}$ to $+9 \cdot 5 \mathrm{D}$ in the sample of 94 .

\section{Method}

The ocular tensions of all subjects were obtained with the applanation tonometer mounted on the Haag-Streit 900 slit lamp. Also available for all subjects were the following measurements:

(i) Depth of the anterior chamber (measured optically with the attachment for the slit lamp); 
(ii) Distance from the anterior corneal surface to the anterior retinal surface, obtained from a combination of optical and ultrasonographic measurements (technique similar to that of Leary, Sorsby, Richards, and Chaston, 1963);

(iii) Refraction of the eye measured objectively and subjectively.

\section{Results}

\section{(A) AXial Length AND APplanation tension}

The relationship between these two was statistically analysed for the 75 subjects in the age group i 8 to 27 years, with the rank correlation method of Spearman. A correlation coefficient of +0.367 which was significant at the 0.2 per cent. level by Student's " $t$ " test was found, i.e. the greater the axial length the higher the ocular tension. A scattergram is shown in the Figure together with the regression line for values of applanation tension on values of axial length. A correlation coefficient of $+0 \cdot 34$, significant at the $0 \cdot I$ per cent. level, was also found from a rank correlation test on the enlarged group of 94 subjects.

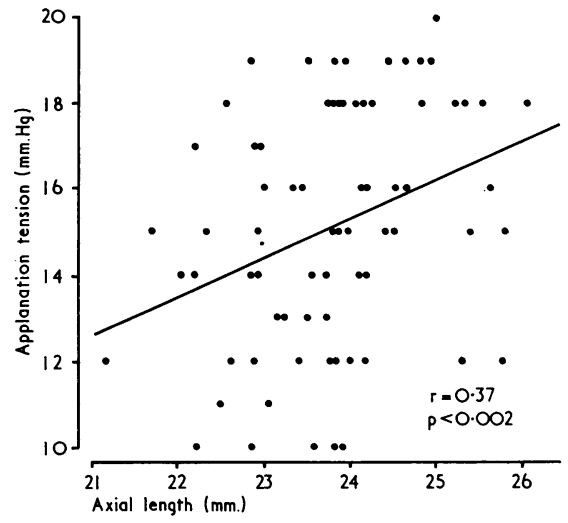

FIGURE Regression line shown on scattergram obtained from data on a group of 75 normal subjects aged 18 to 27 years (myopes 32, emmetropes 27, and hypermetropes 16). Correlation significant at 0.2 per cent. level

(B) REFRAGTION AND APPLANATION TENSIONS

The sample of 94 was subdivided into:

(a) 37 myopes: best sphere refraction more ametropic than $-0.5 \mathrm{D}$.

(b) 22 hypermetropes: best sphere refraction more ametropic than +0.5 D.

(c) 35 emmetropes: best sphere refraction not more ametropic than $\pm 0.5 \mathrm{D}$.

The mean and standard deviation of applanation tensions were found in each group (Table I). A significant difference $(t=2 \cdot 41 ; P<0.02)$ was found between the means

Table I

\begin{tabular}{|c|c|c|}
\hline Refractive group & $\begin{array}{l}\text { Applanation tension (mean } \pm S . D .) \\
(m m . H g)\end{array}$ & $\begin{array}{l}\text { Axial length (mean } \pm S . D .) \\
(\mathrm{mm} .)\end{array}$ \\
\hline Myopia & $15.49 \pm 2.8 I^{*}$ & $24 \cdot 6 \mathrm{I} \pm \mathrm{I} \cdot 00^{*}$ \\
\hline Emmetropia & $14 \cdot 74 \pm 2 \cdot 4^{2}$ & $23 \cdot 40 \pm 1 \cdot 3^{8}$ \\
\hline$\overline{\text { Hypermetropia }}$ & $13.91 \pm 2.28^{*}$ & $22.53 \pm 1.02 *$ \\
\hline
\end{tabular}

* Significant difference between means at 2 per cent. level 
of applanation tensions in the myopic and hypermetropic groups, the former being the greater. This result is consistent with the observation in the previous Section A above. The difference between the emmetropes on the one hand and each of the two groups of ametropes on the other was not significant (myopes $v$. emmetropes $t=1 \cdot 17, P<0 \cdot 25$; hypermetropes $v$. emmetropes $\mathrm{t}=\mathrm{I} \cdot 46, \mathrm{P}<0 \cdot 25$ ), but their mean level of tension fell nicely between the two which indicates some internal consistency.

Of the astigmats in the survey, 65 had less than $\mathrm{ID}$, eight had $>\mathrm{ID}$ but $<2 \mathrm{D}$, and two had $>3 \mathrm{D}$. The range of best sphere refraction for the 18 to 27 year age group was $-7 \mathrm{D}$ to $+4 \cdot 75 \mathrm{D}$, while that for the 18 to 72 year age group was $-9 \cdot{ }_{5} \mathrm{D}$ to $+9{ }_{5} \mathrm{D}$.

(c) SEX AND APPLANATION TENSIONS

The mean and standard deviation of applanation tension and axial length were found for the male and female samples within the age range 18 to 27 years. The males had significantly higher applanation tensions and axial lengths than the females within this age group (Table II, top half).

Table II

\begin{tabular}{|c|c|c|}
\hline Sample & $\begin{array}{l}\text { Applanation tension (mean } \pm S . D .) \\
(m m . H g)\end{array}$ & $\begin{array}{l}\text { Axial length (mean } \pm \text { S.D.) } \\
(\mathrm{mm} .)\end{array}$ \\
\hline $\begin{array}{l}\text { Males } \\
\text { Females }\end{array}$ & $\begin{array}{l}15.58 \pm 2.83^{*} \\
14.25 \pm 2.75^{*}\end{array}$ & $\begin{array}{l}23.98 \pm 1.00^{*} \\
23.50 \pm 0.76^{*}\end{array}$ \\
\hline $\begin{array}{l}\text { Males, chosen with axial lengths } \\
\text { to match closely those of females } \\
\text { Females }\end{array}$ & $\begin{array}{l}15.08 \pm 2.78 \dagger \\
14.25 \pm 2.75 \dagger\end{array}$ & $\begin{array}{l}23.56 \pm 1.08 \dagger \\
23.50 \pm 0.76 \dagger\end{array}$ \\
\hline
\end{tabular}

* Significant difference between means at 5 per cent. level

$\dagger$ Difference between means not significant

In order to assess this sex difference more stringently, a group of males was chosen so that each individual's axial length was matched as closely as possible with that of a female; comparison between applanation tensions of this male "control" group and the female group showed no significant difference (as also, of course, between their axial lengths).

\section{Hypothesis}

The explanation for these findings is not obvious but a common basis is more attractive than two independent ones. One possible explanation is that, at the time when myopia develops, there is a level of production of aqueous humour too great for slightly subnormal outflow channels so that the eyeball distends. As a result, the corneal circumference and the antero-posterior extent of the meshwork probably increase so that a greater crosssectional area of outflow channels is available; thinning of the ciliary body and the sclera may also increase uveo-scleral bulk flow (see Bill, I965): neither of these changes is enough to compensate fully for the higher level of production of aqueous humour, hence the raised pressure in myopic eyes. The opposite explanation may well be true, however: that as a result of the inherited greater axial length of the myopic eyeball, the resistance to outflow of aqueous humour is increased (perhaps mainly by flattening and attenuation of the meshwork); to put this more generally, axial length will be one of the quite important inherited factors in the multifactorial polygenic inheritance of open-angle glaucoma (see Armaly, r967a). 
An attractive feature of either explanation, possibly favouring the first-mentioned, is that compensatory corneal flattening would be easily understood as a coincidental consequence which would contribute to the achievement of emmetropia, and the increase in corneal diameter might be a determining factor in the relatively thinner crystalline lens; perhaps the hypothesis should be restricted only to cases of low myopia, or of emmetropia with a greater than usual axial length, and not applied to high myopia, for which a different (genetic) explanation may exist (Luyckx-Bacus and Weekers, 1967).

Finally, our observations may have another common basis not immediately obvious.

\section{Discussion}

Further evidence for or against that inference would be obtained by a study of tonometry in cohorts of myopes and normals, especially at the age when myopia is starting or quickly progressing. Treatment of developing myopia with drugs to reduce ocular tension would have a rationale-but such treatment, by preventing an increase in axial length, could possibly prevent an increase in outflow of aqueous through conventional channels or through uveo-scleral channels, so that the danger of glaucoma might eventually be increased.

Might the results of this survey be due merely to a tonometric artefact resulting from the tendency for myopic eyes to have flatter corneal curvatures than emmetropic and hypermetropic eyes (Sorsby, Benjamin, Davey, Sheridan, and Tanner, 1957)? This was considered in the light of the work of Schmidt (1956), who has shown that applanation tensions observed in the case of very flat corneal curvatures are greater than those recorded in the case of very steep corneae. Corneal curvature in our survey ranged from $7 \cdot 08$ to $8.55 \mathrm{~mm}$. radius. Over this range of curvature for normal ocular rigidity, Schmidt observed a change of only $0.1 \mathrm{~mm}$. $\mathrm{Hg}$ in applanation tonometry, and we feel therefore justified in accepting for our survey the conclusion of Goldmann (1956) that for "normal limits" the effect of corneal curvature on applanation tension is negligible.

Tonometry artificially raises the intraocular pressure. In an eye with a large volume and low rigidity the rise would be expected to be less than in a small eye. This would tend to discriminate against our finding of high pressure in the eyes with the greater axial length and to neutralize any effect of corneal curvature alone.

Although Armaly (1967b) found no significant sex difference in applanation tensions below the age of 45 years, in our subjects the difference was significant at the 5 per cent. level (see Table II). Possibly there is less inconsistency than might appear because our subjects had a fairly large range of ametropia, and therefore of axial length. Furthermore, as we have mentioned in "Results" above, if a series of males and females, carefully matched for axial length, is examined, no significant difference in pressure is found; these subjects were in the age range 18 to 27 years, but it would be interesting to know if a positive correlation between tension and axial length exists in all age groups.

The observations recorded here are consistent with the high incidence of myopia in patients suffering from simple glaucoma; Perkins and Jay (1960) reported that 22 per cent. of 205 patients with the condition over the age of 50 were myopic; under the age of 50 the incidence of myopia was 37.8 per cent. The high incidence of simple glaucoma in myopic patients has been observed by Weekers, Lavergne, and Prijot (1958) and by DiazDominguez (I96I, I966), who found this incidence in eyes with more than $-20 \mathrm{D}$ of myopia and suggested that malignant myopia may be a specific form of congenital glaucoma. Our results are also consistent with those of Armaly and Sayegh (1969) and 
Armaly (1969), who found, for example, that the cup-to-disc diameter ratio tended to be more frequently $>0.3$ the higher the ocular tension, even though (or perhaps because?) their sample excluded any subject with a distance refraction of greater than ${ }_{3} \mathrm{D}$ myopia or with a history or evidence of ocular disease, injury, or operation; in the older age groups the frequency of large cup-to-disc ratios was greater. Armaly and Sayegh found a negative correlation of cup-to-disc ratio with facility of outflow and have made the suggestion that these genetically determined parameters (applanation tension and facility of outflow) share common determinants. Our observations suggest that a basic common factor is axial length. This concept may be regarded from a more general point of view. Armaly (1965), considering the distribution of applanation pressure in the general population, suggested that this population was made up of statistically different sub-populations, in which age, sex, and family history of glaucoma are three of the determining factors. Our observations seem to justify the suggestion that axial length of the eyeball, which implies in many cases spherical ametropia, should be included among the factors mentioned.

It is at first sight a little surprising that, unlike Armaly and Sayegh (1969), we have found no significant correlation between cup-to-disc ratio and applanation tensions, although we have found that each separately showed a significant correlation with axial length (Tomlinson and Phillips, I969). However, their sample was much larger than ours and we do not consider that there is any true inconsistency between our results. Some support for that may be claimed because Armaly (1969) found the correlation between applanation tensions and cup-to-disc ratio less powerful than that between $\mathrm{C}$ values and cup-to-disc ratios. (We did not include $\mathrm{C}$ values in our study.) We suggest that axial length, which we have shown to be correlated with cup-to-disc ratio (Tomlinson and Phillips, I969), also affects G values via "ocular rigidity", in which total ocular volume or surface area of corneo-scleral envelope (see Phillips and Quick, I96o; Ytteborg, 196o; and Phillips and Shaw, 1970) is probably an important element. A residual effect may be present even if a correction factor for ocular rigidity be included (see Gloster, I966).

\section{Summary}

A group of 37 myopes aged 18 to 72 years showed a mean applanation tension of $15.49 \mathrm{~mm}$. $\mathrm{Hg}$ (S.D. $2 \cdot 8 \mathrm{I}$ ) which was significantly higher than the mean of $13.91 \mathrm{~mm}$. Hg (S.D. 2.28) in a group of 22 hypermetropes. The mean of 35 emmetropes was $14.74 \mathrm{~mm}$. Hg (S.D. $2 \cdot 4^{2}$ ), i.e. nicely between the other two groups; this mean did not differ significantly from the other two.

There was a statistically significant positive correlation between ocular tension and axial length, i.e. the higher the tension the greater the axial length. The group used for this study comprised 75 persons aged 18 to 27 years of the total of 94 mentioned in the preceding paragraph.

Although males had a significantly higher tension than females, they also had significantly larger axial lengths; when a series of male : female pairs was chosen so that each pair had as nearly the same axial length as possible, the differences between the means of the tensions became very small (insignificant), i.e. if the groups were controlled for axial length the sex difference in tension almost disappeared.

These findings are consistent with the recorded statistics which suggest that myopia is more common among patients with open-angle glaucoma than among normal individuals. 
Two possible explanations are immediately obvious: EITHER raised tension is an important factor in producing a large axial length oR the raised tension is produced by a large axial length. However, other common bases for our observations may exist.

\section{Addendum}

Since this paper was written, observations have been published (Abdalla and Hamdi, 1970) showing that in all age groups from I I to over 50 years, except for 21 to 30 years, myopes had significantly higher ocular tensions than emmetropes.

\section{References}

ABDAlla, M. I., and HAMdi, м. (1970) Brit. J. Ophthal., 54, 122

ARMALY, M. F. (1962) Invest. Ophthal., 1, 618

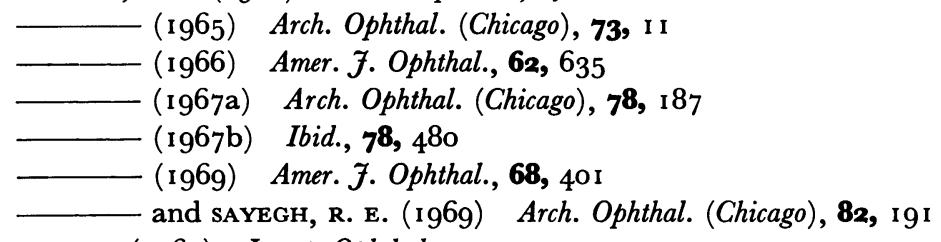

BILL, A. (1965) Invest. Ophthal., 4, 9 I I

DiAZ-Dominguez, D. (1961) Ann. Oculist. (Paris), r94, 597

- (1966) Arch. port. Oftal., 18, 13

GLOSTER, J. (1966) "Tonometry and Tonography", p. 127. Churchill, London

goldmann, H. (1956) "Glaucoma". Transactions of the Second Conference, ed. F. W. Newell,

pp. I89 and 190. Josiah Macy Jr. Foundation, New York

LEARY, G. A., SORSBY, A., RICHARDS, M. J., and chaston, J. (1963) Vision Res., 3, 487

LUYCKX-Bacus, J., and WeEkers, J. F. (1967) Ann. Oculist. (Paris), 200, 489

PERkins, E. s., and JAY, B. s. (1960) Trans. ophthal. Soc. U.K., 80, I 53

PHILliPs, C. I., and QUICK, м. с. (1960) Brit. F. Ophthal., 44, 149

- and shaw, T. L. (1970) Exp. Eye Res., in press

sChmidt, т. (1956) Klin. Mbl. Augenheilk., 129, 196

SORSBy, A., BENJAMin, B., DAVEy, J. B., SHERIDAN, M., and tanNer, J. M. (1957) "Emmetropia and

its Aberrations". Med. Res. Coun. Spec. Rep. Ser., No. 293

TOMLINson, A., and PHILlips, c. I. (1969) Brit. J. Ophthal., 53, 765

Weekers, R., LAVergne, G., and Prijot, E. (1958) Ann. Oculist. (Paiis), 191, 26

ytTEBorg, J. (1960) Acta ophthal. (Kbh.), 38, 643 